\title{
Research Paper: Effects of Pretreatment With Ginseng Extract on Dopamine D2 Receptor Analgesia
}

\author{
Mahnaz Taherianfard $^{1 *}$ (1), Somaye Aalami ${ }^{1}$
}

1. Department of Basic Sciences, School of Veterinary Medicine, Shiraz University, Shiraz, Iran.

\begin{tabular}{l|l|}
$\begin{array}{l}\text { Use vour device to san } \\
\text { and read the artice online }\end{array}$ & $\begin{array}{l}\text { Cftation: Taherianfard, M., \& Aalami, S. (2020). Effects of Pretreatment With Ginseng Extract on Dopamine D2 Receptor } \\
\text { Analgesia. Basic and Clinical Neuroscience, 11(5), 587-594. http://dx.doi.org/10.32598/bcn.9.10.425 }\end{array}$ \\
dol http://dx.doi.org/10.32598/bcn.9.10.425
\end{tabular}

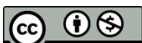

Article info:

Received: 11 Jul 2019

First Revision: 10 Aug 2019

Accepted: 19 Dec 2019

Available Online: 01 Sep 2020

Keywords:

Ginseng, D2 agonist, D2 antagonist, Formalin test

\section{ABSTRACT}

Introduction: The ginseng extract is an herb that has been used for many purposes such as analgesic effect. Dopamine D2 receptors are involved in the regulation of pain in humans. Therefore, the present investigation aims to study how pretreatment with aqueous-alcoholic extract of ginseng can affect dopamine D2 receptors' pain sensitivity.

Methods: We used 45 adult male rats weighing $250 \pm 20$ for this study. Animals were maintained in a standard condition at a temperature of $21{ }^{\circ} \mathrm{C}-24^{\circ} \mathrm{C}$. The experimental groups were as follows: 1. Sham 1 (intraperitoneal [IP] injection of normal saline); 2. Sham 2 (intracerebroventricular [ICV] injection of artificial cerebrospinal fluid [ACSF]); 3. Experimental 1 (IP injection of ginseng extract); 4 and 5. Experimental groups 2 and 3 (IP injection of ginseng extract + bromocriptine 10 and $30 \mu \mathrm{g} /$ rat by ICV injection); 6 and 7) experimental groups 4 and 5 (IP injection of ginseng extract + chlorpromazine 20 and $40 \mu \mathrm{g}$ ) rat by ICV injection). Ginseng extract $100 \mathrm{mg} / \mathrm{kg} / \mathrm{d}$ was used for 7 days. Pain sensitivity test was done in all groups with the formalin test. Lateral ventricles of the rats were cannulated unilaterally by the stereotaxic procedure.

Results: Our data showed that ginseng $(100 \mathrm{mg} / \mathrm{kg} / \mathrm{d})$ significantly $(\mathrm{P}<0.05)$ decreased pain sensitivity compared to the sham 1 group. Bromocriptine in two doses significantly decreased pain sensitivity compared to the sham 2 group. Chlorpromazine in high doses significantly increased pain sensitivity compared to the sham 2 group.

Conclusion: The present results indicate that ginseng can modulate the D2 receptor of the dopamine system in the control of pain sensitivity in the formalin test. Because bromocriptine and ginseng have similar effects, it seems that they had synergistic effects. 


\section{Highlights}

- Ginseng and bromocriptine had an analgesic effect.

- An analgesic effect of ginseng and bromocriptine is synergistic but no additive.

- Hyperalgesic effect of chlorpromazine is more potent than the analgesic effect of ginseng.

\section{Plain Language Summary}

Pain is physical and mental suffering that may arise by internal or external stimuli. Dopamine is one of the main chemical substances of the brain. It seems that the dopamine has analgesic effect. The analgesic effect of dopamine is through dopaminergic D2 receptors. On the other hand, Ginseng is an herbal plant and the roots of this plant contain a class of steroid that is responsible for its pharmacological activity. Ginseng has analgesic, antioxidant, anti-inflammatory, anti-apoptotic, and anti-aging properties. Some investigator stated that ginseng not only cause the release of dopamine directly or indirectly through the cholinergic system, but also can directly affect dopamine D2 receptors. According to the present results, ginseng administration $(100 \mathrm{mg} / \mathrm{kg} /$ day $)$ for 7 days had an analgesic effect, and bromocriptine (D2 receptor agonist) administration in two different doses after pretreatment with ginseng (100 mg/ $\mathrm{kg}$ /day) had an analgesic effect the same as ginseng alone. Therefore, it seems that bromocriptine and ginseng had a synergistic but no additive effect. Finally, chlorpromazine (D2 receptor antagonist) administration in two different doses after pretreatment with ginseng $(100 \mathrm{mg} / \mathrm{kg} /$ day $)$ had hyperalgesic effects compared to ginseng alone. Therefore, the hyperalgesic effect of chlorpromazine is more potent than the analgesic effect of ginseng. According to our data ginseng and D2 receptor agonist had the same analgesic effect.

\section{Introduction}

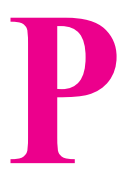

ain is physical and mental suffering that may arise by internal or external stimuli. Pain regulation is a complex process that depends on the interaction of many physiological, neurological, and hormonal factors. By changing the level of chemical mediators, some environmental events reduce or increase pain sensitivity. These chemical mediators are very effective in pain relief (Garland, 2012).

Dopamine is one of the main neurotransmitters of the central nervous system and many neurological and psychiatric diseases are related to its secretion and functions (Dauer \& Przedborski, 2003). It seems that the analgesic effect of the dopaminergic system is through the endogenous opioid receptor (Volkow, 2010). These effects on pain processing are mainly done by striatal dopaminergic D2 receptors (Becker et al., 2013). Besides, it is reported that activation of dopamine D2 receptor through descending endogenous pain-control pathways is essential (Dauer \& Przedborski, 2003).

Ginseng is an herbal plant belonging to the Panax genus of the family Araliaceae (Rhim, Kim, Lee, Oh, \& Nah, 2002). The roots of this plant contain a class of ste- roid glycosides called ginsenoside that is responsible for its pharmacological activity (Chang, Seo, Gyllenhaal, $\&$ Block, 2003). The scientific names of ginsenosides are triterpenoid saponins or sometimes panaxoside in ginseng root (Sun, 2004). Ginseng has antioxidant, anti-inflammatory, anti-apoptotic, and anti-aging properties. These effects include increased neuronal survival, growth, and development of neuron and prevention from neuronal death (Rausch, Liu, Gille, \& Radad, 2006). Kim, Shim, Chung, and Lee (2006) stated that ginseng saponins not only cause the release of dopamine directly or indirectly through the cholinergic system, but also can directly affect dopamine D2 receptors (Kim et al., 2006). On the other hand, ginsenosides have partial neurotrophic and neuroprotective effects on dopaminergic neurons in culture. Therefore, they increase cell survival by decreasing the release of lactate dehydrogenase and preventing mitochondrial membrane potential loss (Sandoval-Avila et al., 2018).

Despite many investigations on dopamine D2 receptor and pain and the relation between ginseng extract and pain, the simultaneous analgesic effect of these two factors has not been evaluated. Therefore, we aimed to investigate the effect of dopamine D2 receptor agonis (bromocriptine) and antagonist (chlorpromazine) on 


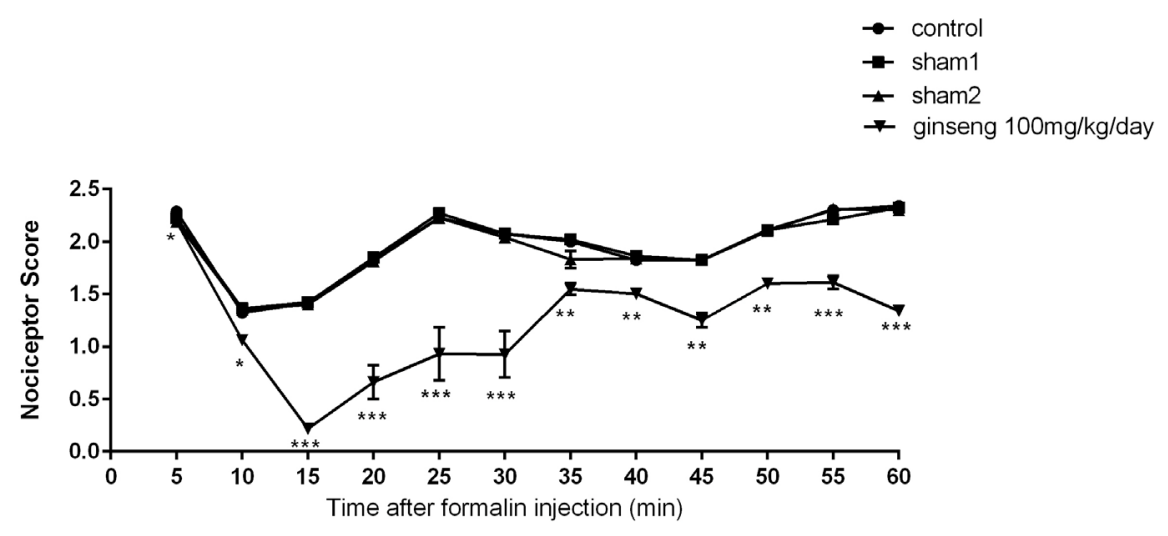

Figure 1. Effect of ginseng $(100 \mathrm{mg} / \mathrm{kg} / \mathrm{d})$ on nociceptive scores (Mean $\pm \mathrm{SE})$

NEUR SCIENCE

* Difference between ginger group in comparison to control, sham 1 and sham 2 groups; ${ }^{*} \mathrm{P}<0.05$, ** $\mathrm{P}<0.01$, *** $\mathrm{P}<0.001$.

pain sensitivity after ginseng extract administration $(100$ $\mathrm{mg} / \mathrm{kg} / \mathrm{d}$ ) for 7 days.

\section{Materials and Methods}

A total number of 56 adult male Wistar rats weighing approximately $250 \pm 20 \mathrm{~g}$ in standard conditions $(12 / 12$ hour light/dark cycle at $22 \pm 2^{\circ} \mathrm{C}$ ) were used. They had access to food and water ad libitum.

The rats were randomly divided into 7 groups $(n=8)$, as follows: 1 . Sham 1: healthy rats received IP injection of normal saline; sham 2 . Rats were unilaterally received Artificial Cerebrospinal Fluid (ACSF) by Intracerebroventricular (ICV) injection into the lateral ventricle; 3. experimental 1: rats received IP injection of ginseng extract; 4 and 5. Experimental 2 and 3: Rats received IP injection of ginseng extract + unilateral ICV injection of bromocriptine 10 or $30 \mu \mathrm{g} / \mathrm{rat} ; 6$ and 7. Experimental 4 and 5: rats received IP injection of ginseng extract + unilateral ICV injection of chlorpromazine 20 or $40 \mu \mathrm{g} / \mathrm{rat}$.

IP injections of normal saline and ginseng extract $(100 \mathrm{mg}$ $\mathrm{kg} / \mathrm{d}$ ) were done for 7 days. Formalin test was performed 30 min after IP injection of normal saline or ginseng extract in the sham 1 and experiment 1 groups and $30 \mathrm{~min}$ after ICV injection in groups that received drugs or ACSF. Hydro-alcoholic extract of ginseng was prepared according to Palaniyandi, Suh, and Yang (2017) study.

To evaluate the pain sensitivity, formalin solution $(50 \mu \mathrm{L})$ was subcutaneously injected into the dorsal surface of the animal's right hind paw ( $2.5 \%$ in normal saline). The pain score was recorded every 15 seconds for 60 minutes. The score would be 0 if the animal showed no reaction, 1 if the animal did not rely on the injected paw, 2 if the animal holds its paw up, and 3 if the rat licks and/or bites the injected paw. The results of all 15-s checks were averaged for every 5 minutes and considered for data analysis.

For the stereotaxic procedure, the animals were anesthetized with an IP injection of ketamine $10 \%(100 \mathrm{mg} / \mathrm{kg})$ and xylazine $2 \%(10 \mathrm{mg} / \mathrm{kg})$. The rats were fixed in the stereotaxic apparatus using blunt ear bars. The skull was carefully exposed and stainless steel guide cannula (23-gauge needle) was inserted unilaterally into the lateral ventricle. The coordinates for lateral ventricle according to bregma were $0.5 \mathrm{~mm}$ anterior and $1.5 \mathrm{~mm}$ lateral to the midline and $3.5 \mathrm{~mm}$ below to cortex. The guide cannula via dental acrylic cement and two tiny stainless steel screws were fixed to the skull. In the end, the animals were given 7 days recovery period.

\subsection{Statistical analysis}

For data analysis, we used SPSS V. 21. The data were analyzed by One-way ANOVA, repeated measure ANOVA, and the Tuckey post-hoc test. P-values less than 0.05 were considered significant.

\section{Results}

According to ANOVA, IP injection of ginseng $100 \mathrm{mg} /$ $\mathrm{kg} / \mathrm{d}$ for 7 days significantly reduced pain sensitivity in the early phase $\left(\mathrm{F}_{9}=61.2, \mathrm{P}=0.0\right)$, intermediate phase $\left(\mathrm{F}_{9}=16.8\right.$, $\mathrm{P}=0.0)$, and late phase $\left(\mathrm{F}_{9}=92.8, \mathrm{P}=0.0\right)$ of formalin test compared to the control and sham1 groups (Figure 1).

One-way ANOVA results indicate that ICV injection of bromocriptine $10 \mu \mathrm{g} / \mathrm{rat}$ after IP injection of ginseng 100 $\mathrm{mg} / \mathrm{kg} / \mathrm{d}$ for 7 days significantly $(\mathrm{P}<0.0001)$ reduced pain sensitivity during 60 minutes of formalin test compared to the control and sham 1 groups. The ICV injection of bromocriptine $30 \mu \mathrm{g} / \mathrm{rat}$ after IP injection of ginseng (100 $\mathrm{mg} / \mathrm{kg} / \mathrm{d}$ ) for 7 days had similar effects except that in the 


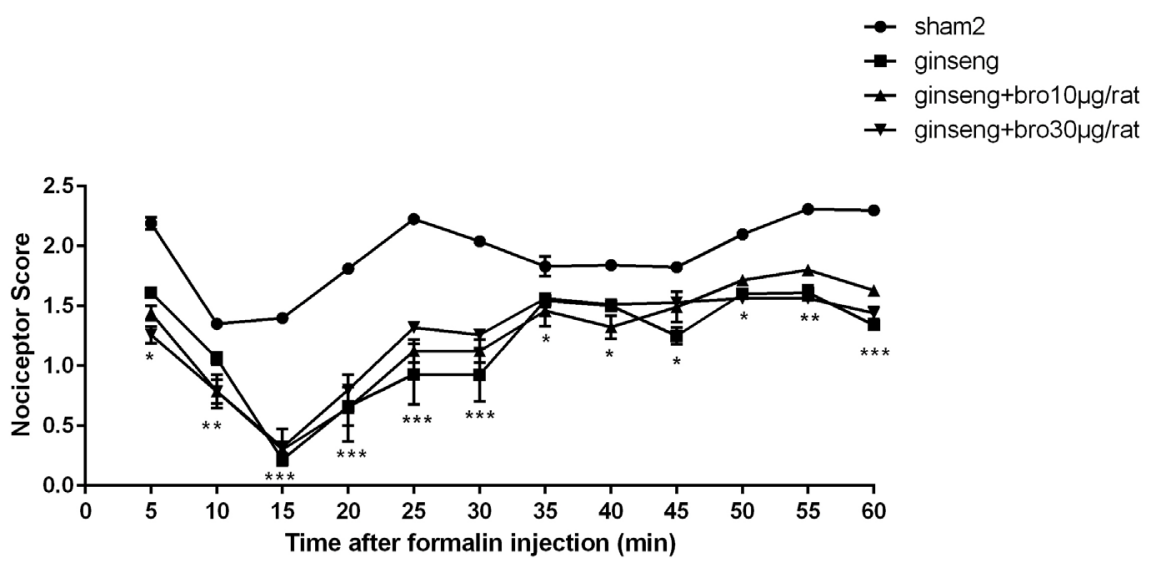

NEUR SCIENCE

Figure 2. Effect of bro (bromocriptine) 10 and $30 \mu \mathrm{g} /$ rat on nociceptive scores (Mean $\pm \mathrm{SE}$ ) in rats pretreated by ginseng (100 $\mathrm{mg} / \mathrm{kg} / \mathrm{d}$ ) for 7 days

* Significant difference between bro 10 and $30 \mu \mathrm{g} /$ rat group in comparison to sham 2 group; ${ }^{\mathrm{P}}<0.05$, ${ }^{* *} \mathrm{P}<0.01$, ${ }^{* * *} \mathrm{P}<0.001$.

25 th and 45 th minutes there was no difference compared to the control and sham 2 groups. Bromocriptine in two doses significantly decrease pain sensitivity in the early phase $\left(\mathrm{F}_{9}=61.2, \mathrm{P}=0.0\right)$, intermediate phase $\left(\mathrm{F}_{9}=16.8\right.$, $\mathrm{P}=0.0)$, and late phase $\left(\mathrm{F}_{9}=92.8, \mathrm{P}=0.0\right)$ of formalin test compared to the control and sham 2 groups but does not have any difference with ginseng group (Figure 2).

Chlorpromazine $(20 \mu \mathrm{g} / \mathrm{rat})$ had no significant effect on pain sensitivity compared to the control and sham 2 groups; while it significantly increased pain sensitivity in the early phase $\left(\mathrm{F}_{9}=61.2, \mathrm{P}=0.0\right)$, intermediate phase $\left(\mathrm{F}_{9}=16.8, \mathrm{P}=0.0\right)$, and late phase $\left(\mathrm{F}_{9}=92.8, \mathrm{P}=0.0\right)$ of formalin test compared with the ginseng group (Figure 3 ). Chlorpromazine $(40 \mu \mathrm{g} / \mathrm{rat})$ significantly increased pain sensitivity in the early phase $(\mathrm{F}=61.2, \mathrm{P}=0.0)$, intermediate phase $\left(\mathrm{F}_{9}=16.8, \mathrm{P}=0.0\right)$ and late phase $\left(\mathrm{F}_{9}=92.8, \mathrm{P}=0.0\right)$ of formalin test compared to the control, sham 2 , and ginseng groups (Figure 3).

\section{Discussion}

The present study demonstrates that the hydro-alcoholic extract of ginseng $100 \mathrm{mg} / \mathrm{kg} / \mathrm{d}$ has an analgesic effect in phase 1 and phase 2 of the formalin test. Previous studies revealed that ginseng saponins have analgesic effects in the writhing test and phase 2 of the formalin test (Nabata, Saito, \& Takagi, 1973; Shin et al., 1997).

The mechanism of the analgesic action of ginseng by formalin test has not been specified, yet. Nevertheless, it is likely that saponins of ginseng attach to the nonopioid receptors at the cell surface and regulate the voltage-gated calcium channels. In other words, the calcium channels are inhibited by ginseng saponins. Volt- age-gated calcium channels play a key role in releasing pain neurotransmitters in presynaptic nerve endings of efferent neurons and its blocking decreases pain to some extent (Nah \& McCleskey, 1994).

The other analgesic mechanism of ginseng in the formalin test is that ginseng saponins or ginsenosides probably affect the dopaminergic activity of the central nervous system (Jun, Bae, Kim, Koo, \& Kim, 2015). Besides the postsynaptic effect of ginseng on voltage-gated channels, it may also affect the presynaptic signal pathway in the dopamine system and thereby increasing dopamine release from nucleus accumbens, as a result, causes pain relief in the formalin test (Mancusoa \& Santangelob, 2017; Nah, Bhatia, Lyles, Ellinwood, \& Lee, 2009).

The present investigation demonstrates that the administration of bromocriptine (10 and $30 \mu \mathrm{g} / \mathrm{rat}$ ) following to hydro-alcoholic extract of ginseng $(100 \mathrm{mg} / \mathrm{kg} / \mathrm{d})$ for 7 days had an analgesic effect as great as ginseng alone in phases of formalin test. Therefore, ginseng extract may apply its analgesic effects through dopaminergic system receptors the same as dopamine. After the injection of a selective dopamine agonist in the nucleus accumbens core, it exerts analgesic effects of dopaminergic drugs in the formalin test (Faramarzi, Zendehdel, \& Haghparast, 2016). Haghparast, Ghalandari-Shamami, \& Hassanpour-Ezatti, (2012) suggested that dopamine D2 receptors in the nucleus accumbens had a critical role in the adjustment of acute and chronic inflammatory pain in the formalin test. Lintas et al. (2011) reported that bilateral microinjection of dopamine D2 receptor agonist in the nucleus accumbens inhibits the chronic phase caused by formalin test. 


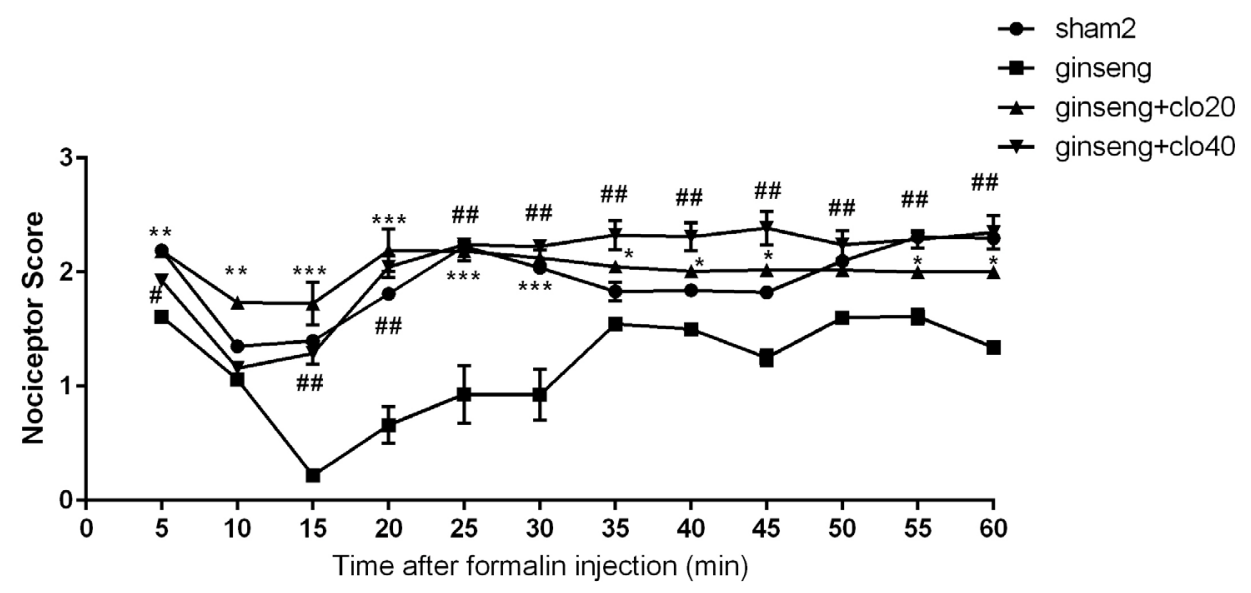

NEUR SCIENCE

Figure 3. Effect of clo (chlorpromazine) 20 and $40 \mu \mathrm{g} /$ rat on nociceptive scores (mean \pm SE) in rats pretreated by ginseng (100 $\mathrm{mg} / \mathrm{kg} / \mathrm{d}$ ) for 7 days

* Significant difference between clo 20 and $40 \mu \mathrm{g} /$ rat groups, in comparison to sham 2 group; \# Significant difference between clo 20 and $40 \mu \mathrm{g} / \mathrm{rat}$ groups, in comparison to ginseng $(100 \mathrm{mg} / \mathrm{kg} / \mathrm{d})$ group.

${ }^{*} \mathrm{P}<0.05,{ }^{* *} \mathrm{P}<0.01,{ }^{* *} \mathrm{P}<0.001 ; \# \mathrm{P}<0.05, \# \# \mathrm{P}<0.001$

There are several mechanisms for analgesic effects of bromocriptine; one of them pointed out that it prevents Nitric Oxide (NO) release by affecting $\alpha 2$-adrenergic receptors (Beck et al., 2004). Some investigations suggest that NO is a modulator of the nervous system in many activities. One of the NO roles is related to pain, because following nerve damages in the affected area, the level of NO increases there (Cury, Picolo, Gutierrez, \& Ferreira, 2011; Levy \& Zochodne, 2004). Moreover, the production of NO, which increases following the formalin test, is inhibited by flavonoids and phenolic compounds of ginseng, thereby decreasing NO that leads to analgesic activity (Jang et al., 2016; Kim et al., 2015). Therefore, ginseng extract and bromocriptine synergistically reduce NO production.

\section{Conclusion}

The current study shows that chlorpromazine in two doses following to IP injection of ginseng $(100 / \mathrm{mg} / \mathrm{kg} / \mathrm{d}) \mathrm{had}$ a hyperalgesic effect compared to the ginseng group. However, its hyperalgesic effect compared to the control and sham 2 groups is seen at $40 \mu \mathrm{g} /$ rat but not $20 \mu \mathrm{g} /$ rat dose.

Various studies show that the raclopride (dopamine D2 antagonist) causes hyperalgesia in rats and pet animals (Da Silva et al., 2017; Dias et al., 2015). Prescription of dopamine antagonists can inhibit the analgesic effect caused by the release of dopamine (Yazdi-Ravandi, Razavi, Haghparast, \& Goudarzvand, 2014). The selective prescription of dopamine D2 receptor antagonists systematically reduces the analgesic effect caused by amphetamines, morphine, and cocaine in the formalin test (Pelissier, Laurido, Hernandez, Constandil, \& Eschalier, 2006). Quinpirole as a dopamine D2-like receptor agonist reduces pain in both phases of the formalin test and sulpiride as an antagonist can potentially reverse analgesic effects observed by this agonist (Shamsizadeh, Pahlevani, Haghparast, Moslehi, \& Zarepour, 2013). These results supported our findings.

According to the present results, ginseng administration $(100 \mathrm{mg} / \mathrm{kg} / \mathrm{d})$ for 7 days had an analgesic effect, and bromocriptine administration in two different doses after pretreatment with ginseng $(100 \mathrm{mg} / \mathrm{kg} / \mathrm{d})$ had an analgesic effect the same as ginseng alone. Therefore, it seems that bromocriptine and ginseng had a synergistic but no additive effect. Finally, chlorpromazine administration in two different doses after pretreatment with ginseng $(100 \mathrm{mg} / \mathrm{kg} / \mathrm{d})$ had hyperalgesic effects compared to ginseng alone. Therefore, the hyperalgesic effect of chlorpromazine is more potent than the analgesic effect of ginseng.

\section{Ethical Considerations}

\section{Compliance with ethical guidelines}

All animal procedures were performed according to the Institutional Research Ethics Committee of the School of Veterinary Medicine of Shiraz University, Shiraz, Iran. 


\section{Funding}

This study was financially supported by Shiraz University (Grant: 94GCU4M1755).

\section{Authors' contributions}

Conceptualization, methodology, software, validation, formal analysis, investigation, resources, data curation, writing - original draft preparation, writing - review \& editing, visualization, supervision, and project administration, funding acquisition: Mahnaz Taherianfard; Methodology, investigation, resources, data curation: Somaye Aalam.

\section{Conflict of interest}

All authors declared no conflict of interest.

\section{References}

Beck, G., Brinkkoetter, P., Hanusch, C., Schulte, J., van Ackern, K., van der Woude, F. J., et al. (2004). Clinical review: Immunomodulatory effects of dopamine in general inflammation. Critical Care, 8(6), 485-91. [DOI:10.1186/cc2879] [PMID] [PMCID]

Becker, S., Ceko, M., Louis-Foster, M., Elfassy, N. M., Leyton, M., Shir, Y., et al. (2013). Dopamine and pain sensitivity: Neither sulpiride nor acute phenylalanine and tyrosine depletion have effects on thermal pain sensations in healthy volunteers. PLoS One, 8(11), e80766. [DOI:10.1371/journal.pone.0080766] [PMID] [PMCID]

Chang, Y. S., Seo, E. K., Gyllenhaal, C., \& Block, K. I. (2003). Panax ginseng: A role in cancer therapy? Integrative Cancer Therapies, 2(1), 13-33 [DOI:10.1177/1534735403251167] [PMID]

Cury, Y., Picolo, G., Gutierrez, V. P., \& Ferreira, S. H. (2011). Pain and analgesia: The dual effect of nitric oxide in the nociceptive system. Nitric Oxide, 25(3), 243-54 [DOI:10.1016/j.niox.2011.06.004] [PMID]

DaSilva, A. F., Nascimento, T. D., Jassar, H., Heffernan, J., Toback, R. L., Lucas, S., et al. (2017). Dopamine D2/D3 imbalance during migraine attack and allodynia in vivo. Neurology, 88(17), 1634-41 [DOI:10.1212/WNL.0000000000003861] [PMID] [PMCID]

Dauer, W., \& Przedborski, S. (2003). Parkinson's disease: Mechanisms and models. Neuron, 39(6), 889-909. [DOI:10.1016/S08966273(03)00568-3]

Dias, E. V., Sartori, C. R., Mariao, P. R., Vieira, A. S., Camargo, L. C., Athie, M. C., et al. (2015). Nucleus accumbens dopaminergic neurotransmission switches its modulatory action in chronification of inflammatory hyperalgesia. European Journal of Neuroscience, 42(7), 2380-9. [DOI:10.1111/ejn.13015] [PMID]

Faramarzi, G., Zendehdel, M., \& Haghparast, A. (2016). D1- and D2-like dopamine receptors within the nucleus accumbens contribute to stress-induced analgesia in formalin-related pain behaviours in rats. European Journal of Pain, 20(9), 1423-32. [DOI:10.1002/ejp.865] [PMID]

Garland, E. L. (2012). Pain processing in the human nervous system: A selective review of nociceptive and biobehavioral pathways. Primary Care, 39(3), 561-71. [DOI:10.1016/j.pop.2012.06.013] [PMID] [PMCID]

Haghparast, A., Ghalandari-Shamami, M., \& Hassanpour-Ezatti, M. (2012). Blockade of D1/D2 dopamine receptors within the nucleus accumbens attenuated the antinociceptive effect of cannabinoid receptor agonist in the basolateral amygdala. Brain Research, 1471, 23-32 [DOI:10.1016/j.brainres.2012.06.023] [PMID]

Jang, K. J., Choi, S. H., Yu, G. J., Hong, S. H., Chung, Y. H., Kim, C. H., et al. (2016). Anti-inflammatory potential of total saponins derived from the roots of Panax ginseng in lipopolysaccharideactivated RAW 264.7 macrophages. Experimental and Therapeutic Medicine, 11(3), 1109-15. [DOI:10.3892/etm.2015.2965] [PMID] [PMCID]

Jun, Y. L., Bae, C. H., Kim, D., Koo, S., \& Kim, S. (2015). Korean Red Ginseng protects dopaminergic neurons by suppressing the cleavage of p35 to p25 in a Parkinson's disease mouse model. Journal of Ginseng Research, 39(2), 148-54. [DOI:10.1016/j. jgr.2014.10.003] [PMID] [PMCID]

Kim, S. E., Shim, I., Chung, J. K., \& Lee, M. C. (2006). Effect of ginseng saponins on enhanced dopaminergic transmission and locomotor hyperactivity induced by nicotine. Neuropsychopharmacology, 31(8), 1714-21. [DOI:10.1038/sj.npp.1300945] [PMID]

Kim, Y. O., Kim, Y., Lee, K., Na, S. W., Hong, S. P., Valan Arasu, M., et al. (2015). Panax ginseng improves functional recovery after contusive spinal cord injury by regulating the inflammatory response in rats: An in vivo study. Evidence-Based Complementary and Alternative Medicine, 2015, 817096. [DOI:10.1155/2015/817096] [PMID] [PMCID]

Levy, D., \& Zochodne, D. W. (2004). No pain: Potential roles of nitric oxide in neuropathic pain. Pain Practice, 4(1), 11-18. [DOI:10.1111/j.1533-2500.2004.04002.x] [PMID]

Lintas, A., Chi, N., Lauzon, N. M., Bishop, S. F., Gholizadeh, S., Sun N., et al. (2011). Identification of a dopamine receptor-mediated opiate reward memory switch in the basolateral amygdala-nucleus accumbens circuit. The Journal of Neuroscience, 31(31), 11172 83. [DOI:10.1523/JNEUROSCI.1781-11.2011] [PMID] [PMCID]

Mancusoa, C., \& Santangelob, R. (2017). Panax ginseng and Panax quinquefolius: From pharmacology to toxicology. Food and Chemical Toxicology, 107(Part A), 362-72. [DOI:10.1016/j. fct.2017.07.019] [PMID] [PMCID]

Nabata, H., Saito, H., \& Takagi, K. (1973). Pharmacological studies of neutral saponins (GNS) of panax ginseng root. The Japanese Journal of Pharmacology, 23(1), 29-41 [DOI:10.1254/jjp.23.29] [PMID]

Nah, S. Y., Bhatia, K. S., Lyles, J., Ellinwood, E. H., \& Lee, T. H. (2009). Effects of ginseng saponin on acute cocaine-induced alterations in evoked dopamine release and uptake in rat brain nucleus accumbens. Brain Research, 1248, 184-90. [DOI:10.1016/j. brainres.2008.10.064] [PMID] [PMCID]

Nah, S. Y., \& McCleskey, E. W. (1994). Ginseng root extract inhibits calcium channels in rat sensory neurons through a similar path but different receptor, as mu-type opioids. Journal of Ethnopharmacology, 42(1), 45-51. [DOI:10.1016/0378-8741(94)90022-1] 
Palaniyandi, S. A., Suh, J. W., \& Yang, S. H. (2017). Preparation of Ginseng Extract with Enhanced Levels of Ginsenosides Rg1 and Rb1 Using High Hydrostatic Pressure and Polysaccharide Hydrolases. Pharmacognosy Magazine, 13(Suppl 1), S142-S147. [DOI:10.4103/0973-1296.203992] [PMID] [PMCID]

Pelissier, T., Laurido, C., Hernandez, A., Constandil, L., \& Eschalier, A. (2006). Biphasic effect of apomorphine on rat nociception and effect of dopamine D2 receptor antagonists. European Journal of Pharmacology, 546(1-3), 40-7. [DOI:10.1016/j.ejphar.2006.06.081] [PMID]

Rausch, W. D., Liu, S., Gille, G., \& Radad, K. (2006). Neuroprotective effects of ginsenosides. Acta Neurobiologiae Experimentalis Journal, 66(4), 369-75. [PMID]

Rhim, H., Kim, H., Lee, D. Y., Oh, T. H., \& Nah, S. Y. (2002). Ginseng and ginsenoside Rg3, a newly identified active ingredient of ginseng, modulate $\mathrm{Ca}_{2}{ }^{+}$channel currents in rat sensory neurons. European Journal of Pharmacology, 436(3), 151-158. [DOI:10.1016/ S0014-2999(01)01613-2]

Sandoval-Avila, S., Diaz, N. F., Gómez-Pinedo, U., CanalesAguirre, A. A., Gutiérrez-Mercado, Y. K., Padilla-Camberos, E., et al. (2018). Neuroprotective effects of phytochemicals ondopaminergic neuron cultures. Neurologia, 34(2), 114-24. [DOI:10.1016/j.nrleng.2016.04.014]

Shamsizadeh, A., Pahlevani, P., Haghparast, A., Moslehi, M., \& Zarepour, L. (2013). Involvement of dopamine receptors within the dorsal hippocampus in suppression of the formalin-induced orofacial pain. Pharmacology Biochemistry and Behavior, 114-115, 37-42. [DOI:10.1016/j.pbb.2013.10.029] [PMID]

Shin, Y. H., Kim, S. C., Han, J. W., Kim, D. H., Han, S. S., Shin, D. H., et al. (1997). Study on ginseng protopanaxadiol and protopanaxatriol saponins-induced antinociception. The Korean Journal of Physiology \& Pharmacology, 1(2), 143-9. https:/ / www. koreascience.or.kr/article/JAKO199703039540433.pdf

Sun, L. Q. (2004). Information on research and application of Ginseng; the king of traditional and herbal medicines. Asian Journal of Drug Metabolism and Pharmacokinetics, 4(4), 264-82. https://www.researchgate.net/publication/266372364

Volkow, N. D. (2010). Opioid-dopamine interactions: Implications for substance use disorders and their treatment. Biological Psychiatry, 68(8), 685-86. [DOI:10.1016/j.biopsych.2010.08.002] [PMID] [PMCID]

Yazdi-Ravandi, S., Razavi, Y., Haghparast, A., \& Goudarzvand, M. (2014). Orexin a induced antinociception in the ventral tegmental area involves D1 and D2 receptors in the nucleus accumbens. Pharmacology Biochemistry and Behavior, 126, 1-6 [DOI:10.1016/j.pbb.2014.08.009] [PMID] 
This Page Intentionally Left Blank 